\title{
Critical porosity of gas enclosure in polar firn independent of climate
}

\author{
Christoph Florian Schaller ${ }^{1}$, Johannes Freitag ${ }^{1}$, and Olaf Eisen ${ }^{1,2}$ \\ ${ }^{1}$ Alfred Wegener Institute, Helmholtz Centre for Polar and Marine Research, 27568 Bremerhaven, Germany \\ ${ }^{2}$ Department of Geosciences, University of Bremen, 28359 Bremen, Germany \\ Correspondence to: Christoph Florian Schaller (christoph.schaller@awi.de)
}

Received: 14 July 2017 - Discussion started: 31 July 2017

Revised: 17 October 2017 - Accepted: 20 October 2017 - Published: 24 November 2017

\begin{abstract}
In order to interpret the paleoclimatic record stored in the air enclosed in polar ice cores, it is crucial to understand the fundamental lock-in process. Within the porous firn, bubbles are sealed continuously until the respective horizontal layer reaches a critical porosity. Presentday firn air models use a postulated temperature dependence of this value as the only parameter to adjust to the surrounding conditions of individual sites. However, no direct measurements of the firn microstructure could confirm these assumptions. Here we show that the critical porosity is a climate-independent constant by providing an extensive data set of micrometer-resolution 3-D X-ray computer tomographic measurements for ice cores representing different extremes of the temperature and accumulation ranges. We demonstrate why indirect measurements suggest a climatic dependence and substantiate our observations by applying percolation theory as a theoretical framework for bubble trapping. The incorporation of our results significantly influences the dating of trace gas records, changing gas-ageice-age differences by up to more than 1000 years. This may further help resolve inconsistencies, such as differences between East Antarctic $\delta^{15} \mathrm{~N}$ records (as a proxy for firn height) and model results. We expect our findings to be the basis for improved firn air and densification models, leading to lower dating uncertainties. The reduced coupling of proxies and surrounding conditions may allow for more sophisticated reinterpretations of trace gas records in terms of paleoclimatic changes and will benefit the development of new proxies, such as the air content as a marker of local insolation.
\end{abstract}

\section{Introduction}

Air trapped in polar ice cores provides a unique opportunity for paleoclimatic studies (Legrand and Mayewski, 1997). In particular, it allows the reconstruction of the past chemical and isotopic composition of the atmosphere for up to 800000 years (Jouzel et al., 2007; Loulergue et al., 2008). However, as bubbles are only isolated from the atmosphere at certain depth (the firn-ice transition - 50-120 m depending on the local conditions), the enclosed air is always younger than the surrounding ice. An accurate estimation of this gas-age-ice-age difference ( $\triangle$ age, up to 7000 years during glacial periods; Bender et al., 2006) is essential for the interpretation of ice-core records as otherwise phase relationships between ice and gas records cannot be determined correctly.

Thus, it is crucial to understand the fundamental processes in the porous firn (Schwander and Stauffer, 1984) - diffusion of air through the open pore space (Trudinger et al., 1997; Fabre et al., 2000) and the entrapment of air by pore closure due to firn densification, which is the main focus of this study. In a depth range referred to as the "lock-in zone", gas enclosure within individual horizontal layers occurs at a critical porosity (Schwander et al., 1993). It is the only parameter in empirical relations of closed and total porosity (Schwander, 1989; Goujon et al., 2003) that are commonly used in present-day firn air models (Severinghaus and Battle, 2006; Mitchell et al., 2015). A temperature dependence of this value has been postulated (Raynaud and Lebel, 1979) and parametrized using air-content measurements (Martinerie et al., 1992). Nonetheless, the underlying microstructural processes are not well-understood and there is no confirmation of these assumptions by direct measurements of firn microstructure. 
(a)

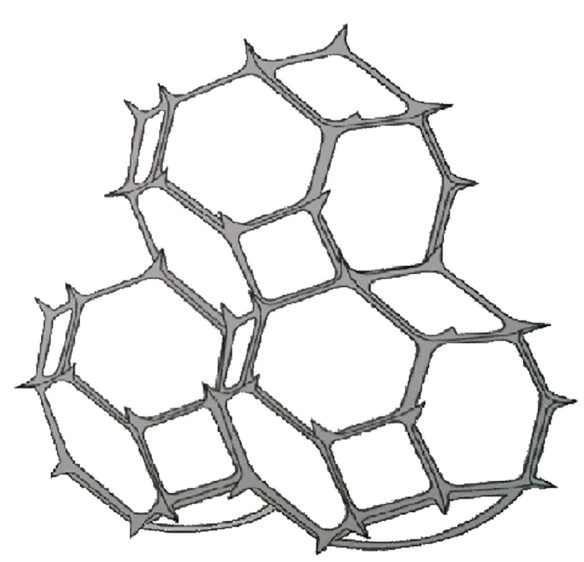

(b)

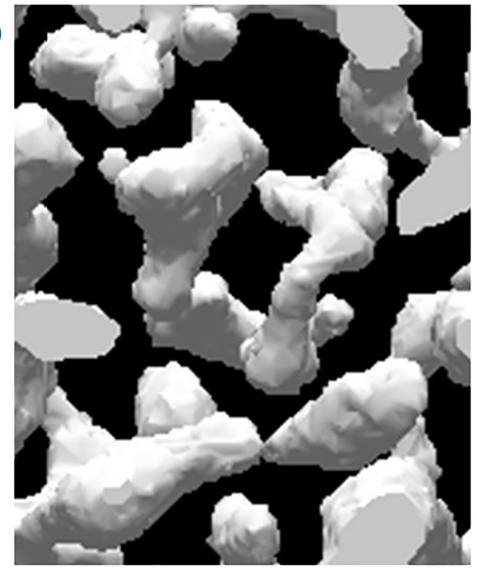

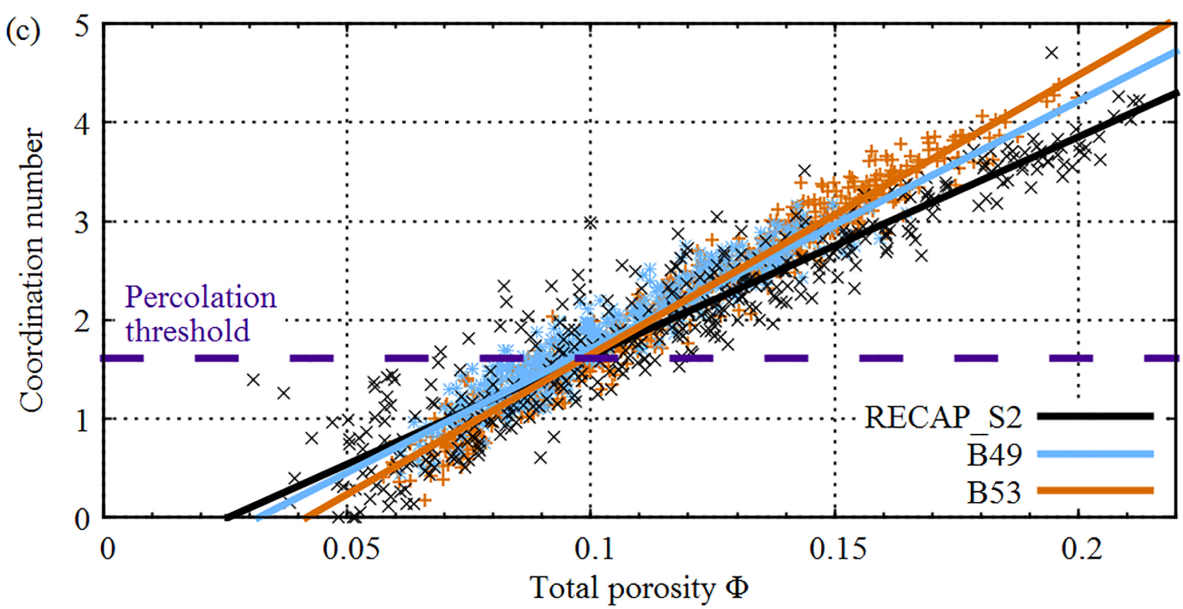

Figure 1. (a) A structure consisting of three packed tetrakaidecahedra. The white bodies represent ice crystals, the gray edges the pore network. (b) Example of a 3-D scan; the pore network is shown in white. (c) Coordination number versus total porosity for our measurements. The threshold for gas enclosure within a single layer as predicted by percolation theory has been marked.

Table 1. Details on the analyzed cores. Mean annual temperature is denoted by $\bar{T}$ and an estimate of yearly accumulation by $\dot{a}$.

\begin{tabular}{llrrrrr}
\hline Drill site & Year & $\begin{array}{r}\text { Elevation } \\
(\mathrm{m})\end{array}$ & $\begin{array}{r}\bar{T} \\
\left({ }^{\circ} \mathrm{C}\right)\end{array}$ & $\begin{array}{r}\dot{a} \\
\left(\mathrm{~kg} \mathrm{~m}^{-2} \mathrm{a}^{-1}\right)\end{array}$ & $\begin{array}{r}\text { Depth interval } \\
(\mathrm{m})\end{array}$ & $\begin{array}{r}\text { No. of } \\
\text { data points }\end{array}$ \\
\hline RECAP_S2 (Renland, Greenland) $^{1}$ & 2015 & 2296 & -18 & 460 & $49-73$ & 246 \\
B49 (Kohnen station, East Antarctica) $^{2}$ & $2012 / 13$ & 2881 & -44 & 65 & $73-90$ & 303 \\
B53 (Dome Fuji, East Antarctica) $^{2}$ & $2012 / 13$ & 3726 & -55 & 30 & $76-106$ & 614 \\
\hline
\end{tabular}

${ }^{1}$ Johnsen et al. (1992). ${ }^{2}$ Unpublished data, the accumulation rates are based on a preliminary volcanic layer dating.

The $\delta^{15} \mathrm{~N}$ of $\mathrm{N}_{2}$ has been established as a proxy for firn height and thus an indirect constraint on $\Delta$ age (Sowers et al., 1992). This relation has successfully been tested for highaccumulation sites, e.g., the last 40000 years at Summit, Greenland (Schwander et al., 1997). On the contrary, there is a mismatch of up to 2000 years with model results for the East Antarctic plateau (Bender et al., 2006; Parrenin et al., 2012). These modeled chronologies are based on the current knowledge of bubble trapping in polar firn and are particularly sensitive to the critical porosity via the assumed temper- ature dependence. Deviations from the simple relationships used to reconstruct past temperatures and accumulation rates from the water isotopic composition have been suggested as a possible explanation (Landais et al., 2006), while the hypothesis of a large glacial convective zone as an important factor has been ruled out (Capron et al., 2013). Recently, the inclusion of impurity effects has reduced the mismatch for East Antarctic sites; however, it reduces the agreement between modeled and measured $\delta^{15} \mathrm{~N}$ for high-accumulation sites (Breant et al., 2017). 
Table 2. Results of least squares fitting our parametrization to the obtained data.

\begin{tabular}{lrrrrr}
\hline Data set & $\Phi_{\text {crit }}$ & $\lambda_{1}$ & $\lambda_{2}$ & $b$ & $R^{2}$ \\
\hline RECAP_S2 & 0.1005 & 62.45 & 47.34 & 0.4816 & 0.9744 \\
B49 & 0.0985 & 169.57 & 51.55 & 0.5797 & 0.9801 \\
B53 & 0.1000 & 206.36 & 48.06 & 0.7072 & 0.9603 \\
\hline
\end{tabular}

In this paper, we present the first extensive data set of direct firn microstructure measurements throughout the lock-in zone. We start off by using it to scrutinize the current knowledge of gas enclosure in polar firn and show why previous indirect measurements yielded different results. Then, we apply bond percolation theory (Enting, 1993) as a theoretical framework for our conclusions and demonstrate their agreement with other methods. Finally, we discuss changes in the dating and interpretation of trace-gas records that incorporation of our results in current firn air models will imply. The reduced coupling of proxies and surrounding conditions may allow for more sophisticated reinterpretations in terms of paleoclimatic changes and will benefit the development of new proxies, such as the air content as a marker of local insolation (Raynaud et al., 2007; Eicher et al., 2016).

\section{Materials and methods}

Firn microstructure throughout the lock-in zone has been deduced for ice cores from three locations (cf. Table 1) using a specifically designed X-ray microfocus computer tomograph in a cold lab (Freitag et al., 2013). For each $1 \mathrm{~m}$ core segment, we scanned a minimum number of five sections of approximately $4 \mathrm{~cm}$ height and the full core diameter $(8-10 \mathrm{~cm})$ with a focus on homogenous layers. One measurement consists of 3000 radioscopic images, which are used to tomographically reconstruct the 3-D microstructure at a resolution of approximately $25 \mu \mathrm{m}$ (e.g., Fig. 1b). Consecutively, these reconstructions are segmented into ice and air using a two-step procedure consisting of a two-level Otsu's method (Otsu, 1979) followed by simple region growing for the ambiguous voxels. We adapted an existing algorithm (Nguyen et al., 2011) to determine the pore coordination number during the segmentation process. To eliminate the effect of cut pores at the surface of the sample (Martinerie et al., 1990), each data point (as referred to, e.g., in Table 1) corresponds to a layer of approximately $1 \mathrm{~cm}$ height and $6 \mathrm{~cm}$ diameter. Having the microstructure of the surrounding material in all directions at hand allows us to safely determine whether a pore is open or closed. For all measurements, the remaining cut pores were less than $0.1 \%$ of the pore volume. For 10 repeat measurements of the same sample, both standard and maximum deviation of the total porosity are less than $1 \%$. Furthermore, the total porosities agree with those from bulk measurements and 2-D radioscopy with a maximum deviation of $3 \%$.
A well-known framework to model porous media is bond percolation theory (Broadbent and Hammersley, 1957). It enables us to predict the point at which a material becomes impermeable. The Kelvin structure (packed tetrakaidecahedra; see Fig. 1a) is space-filling with one of the lowest surfacearea-to-volume ratios. It is well-studied and has for example been applied as a model for foam (Koehler et al., 1999). We use it to represent sintered ice grains. When packed, the grains align along a body-centered cubic lattice. Therefore, the air network corresponds to its dual lattice, which has a coordination number (average number of neighbors) of 4 when fully occupied. For this lattice, the fraction of channels occupied by air at gas enclosure, the so-called percolation threshold, is known to be 0.4031 (van der Marck, 1997). Thus, the predicted coordination number at the percolation threshold is $4 \cdot 0.4031=1.6124$. Notably, the influence of the chosen lattice is rather small (Wierman and Naor, 2003).

\section{Results}

Gas enclosure within a single layer occurs at the same critical porosity $\Phi_{\text {crit }}$ of about 0.1 for all cores (Fig. 2a). However, as indicated by the much steeper slope of the closed porosity, enclosure takes place in a significantly smaller porosity range for the East Antarctic cores compared to the coastal Greenland site. To fit our data, we derived a new local relation (Eq. 1) of closed porosity $\Phi_{\mathrm{cl}}$ and total porosity $\Phi$, where $b, \lambda_{1}, \lambda_{2} \in \mathrm{IR}_{\geq 0}$ and $b \leq 1$. The parameters of least squares fitting are given in Table 2 .

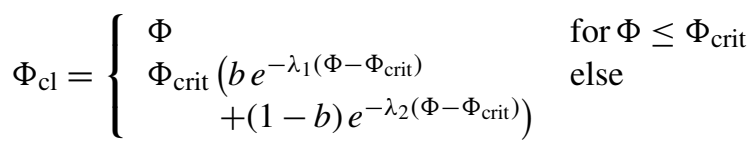

Within the microstructure analysis for the B53 core, we also mimicked the sample properties (cylindrical shape, $5 \mathrm{~cm}$ diameter, $5 \mathrm{~cm}$ height) and the method (melting the sample under vacuum conditions, thus counting cut closed pores as part of the open pore space) as applied for Summit, Greenland (Schwander et al., 1993). This significantly changes the shape of the closed versus total porosity curve and yields results similar to previous studies (Fig. 2b). Then, by comparing with our original data (where cut pores are traced within a larger volume to determine whether they are open or closed), we determined the necessary correction factors for the effect of cut pores (Fig. 4).

For the coordination number (Fig. 1c) we observe a linear increase with total porosity for all three sites. At the critical porosity of about 0.1 , we obtain very similar values of $1.65 \pm 0.17$ for B53, $1.7 \pm 0.18$ for B49 and $1.64 \pm 0.24$ for RECAP_S2 from linear regression. 

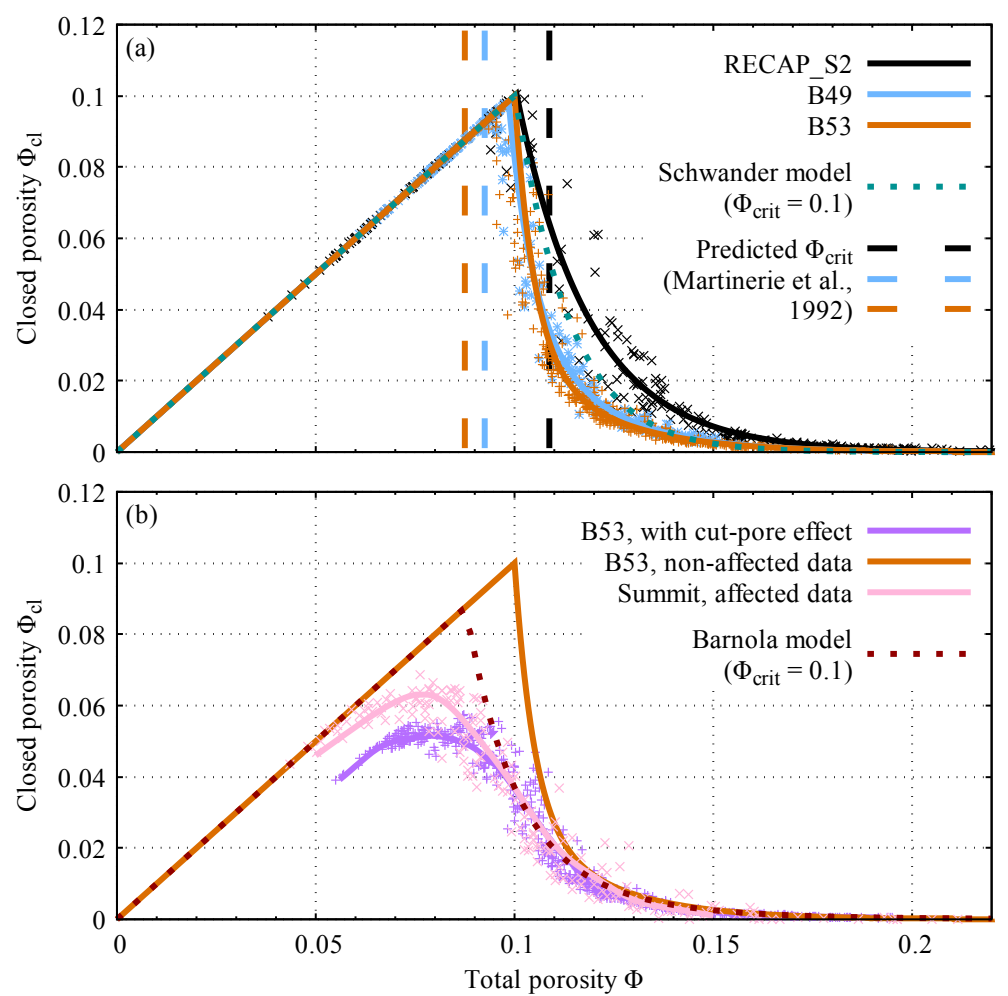

Figure 2. Closed versus total porosity for (a) the analyzed cores in comparison with commonly expected values and (b) B53 ignoring cut pores compared to previous results from Summit, Greenland (Schwander et al., 1993). The solid lines indicate least squares fits for the respective core, the short-dashed lines represent model results (Schwander, 1989; Goujon et al., 2003) for the given parameters, and the long-dashed lines mark the critical porosity values predicted by the previously observed temperature dependence (Martinerie et al., 1992).

\section{Discussion}

Even though the surrounding conditions differ significantly, we obtain the same critical porosity of about 0.1 for all cores (Fig. 2a, Table 2). In previous literature, average ice densities at air isolation were obtained from air-content measurements on deep ice samples (Martinerie et al., 1992). To allow for a better comparison with our results, we calculated the corresponding critical porosities (Fig. 3). For the gas enclosure within single layers, we do not observe the commonly assumed temperature dependence of $\Phi_{\text {crit }}$. In contrast, we find strong evidence for a constant (and thus climateindependent) critical porosity.

In order to estimate the closed porosity in firn, previous studies relied on measuring the amount of air enclosed in a sample by melting it in a vacuum chamber. However, during vacuumization, air is not only removed from the open pore space but also cut closed pores, which is of particular importance for the more extensive pore network of the firn compared to deeper ice samples. The breaking of closed, but still fragile pores might even enhance this effect (Schwander and Stauffer, 1984). Nonetheless, to date, it has been neglected or only accounted for by multiplying with correction factors of up to $10 \%$ (first applied for firn in Appendix 2 of Mar- tinerie et al., 1992; recently, Mitchell et al., 2015). Our estimation (Figs. $2 b$ and 4 ) proves a serious underestimation of the cut-pore effect. This can be explained by a classical percolation phenomenon - near the percolation threshold, individual (clusters of) closed pores can be very large compared to single bubbles (Stauffer, 1979). Indeed, we observe extents of more than $1 \mathrm{~cm}$ near the critical porosity for all three cores.

In particular, our results confirm the existence of a critical porosity in contrast to recent assumptions of gas enclosure for a single layer occurring within a certain porosity range (Mitchell et al., 2015). Remarkably, for the correct critical porosity, the Schwander parametrization (Schwander, 1989) seems to approximately represent a site-independent average relation of closed and total porosity (cf. Fig. 2a). However, due to the lack of other parameters, it cannot fully reflect the behavior of polar firn. Therefore, we decided to derive a more complex exponential-decay relation (Eq. 1) to fit our results.

For all three cores, the observed coordination numbers at gas enclosure (Fig. 1c) are in agreement with the value predicted by percolation theory. We conclude that polar firn evolves towards the same "optimal" microstructure, driven by a universal percolation process (Enting, 1993). However, 


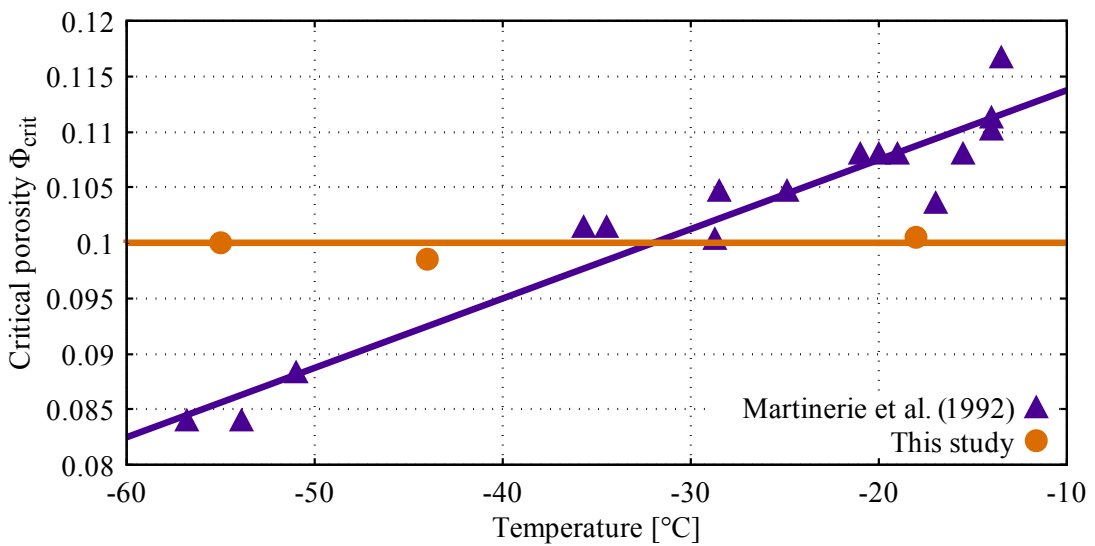

Figure 3. Critical porosity versus temperature. The given linear relation is commonly fit to the data of Martinerie et al. (1992), a study based on air-content measurements of 495 deep ice samples from 16 cores (with a minimum of only two measurements for one core). From their results, they reconstruct the average ice density at air isolation, which is equivalent to the porosities shown here. In contrast, we analyzed the microstructure of 1163 firn samples for three cores (see Table 1), allowing the direct determination of the critical porosity of gas enclosure within a single layer.

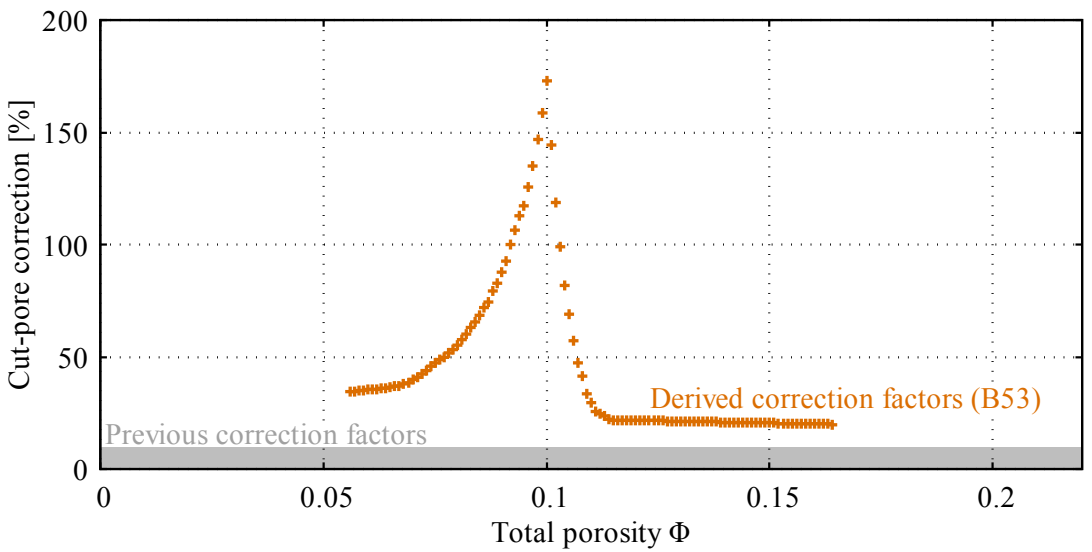

Figure 4. Necessary correction factors for the cut-pore effect assuming the B53 core would have been analyzed with the method used for Summit, Greenland (Schwander et al., 1993). The range of corrections applied in previous literature is indicated by the gray box.

the initial conditions differ as the firn is strongly influenced by the surrounding local conditions such as accumulation rate (affecting residence times at certain depth intervals) and temperature (as one of the main drivers for snow and firn metamorphism; Schneebeli and Sokratov, 2004).

The problem of understanding gas enclosure in polar firn has been tackled with different methods and from various perspectives such as firn microstructure, firn air transport and firn air pumpings. As a consequence, seemingly different definitions have been established for terminological frameworks such as the lock-in zone. The results of two firn air pumpings conducted at the RECAP drill site (T. Sowers, personal communication, 2017) and at Kohnen station, close to B49 (Weiler, 2008), in combination with high-resolution Xray porosity measurements (Freitag et al., 2013) corroborate our microstructural findings. For both sites, the sharp decline in $\mathrm{CO}_{2}, \mathrm{CH}_{4}$ and $\mathrm{N}_{2} \mathrm{O}$ concentrations (interpreted as the on- set of the lock-in zone according to firn air pumpings) coincides with the occurrence of the first significant (i.e., at least $1 \mathrm{~cm}$ thick) layer with a porosity below the critical value of 0.1 . On the other hand, no more air can be pumped (bottom of the lock-in zone according to firn air pumpings) when there are no further layers with a total porosity larger than 0.1. In the firn air transport literature (e.g., Buizert and Severinghaus, 2016), the onset of the lock-in zone (also referred to as "lock-in depth") is defined as the depth where molecular diffusion effectively ceases. According to percolation theory, this happens at the percolation threshold, i.e., the point when there is no longer a connected component of the order of the system size (Ghanbarian and Hunt, 2014). This corresponds to the first layer reaching a closed porosity of $100 \%$, which is the onset of the lock-in zone in the microstructural sense. Regarding the bottom of the lock-in zone, it has been observed that due to vertical mixing, the air composition at a 
certain depth no longer changes (definition according to gas transport) at the "close-off depth" (Buizert et al., 2012). It is defined as the depth at which all pores are closed (Witrant et al., 2012) and thereby also coincides with the bottom of the lock-in zone according to firn microstructure. Thus, the three definitions for the lock-in zone (according to firn microstructure, firn air transport and firn air pumpings) are equivalent. Furthermore, the limits of the lock-in zone are solely determined by the existence of significant layers above and below the critical porosity and thereby the (centimeter-scale) porosity variability.

While concepts such as gas enclosure (both in single layers and as a bulk property) occurring at a critical closed (Goujon et al., 2003) or open (Gregory et al., 2014) porosity have become widely accepted, they do not seem to agree with the results of our firn microstructure analysis and the previously discussed (conceptual) definitions of the lock-in zone. As a consequence, the refinement of these theories may greatly benefit the understanding of gas enclosure in polar firn. Notably, the critical closed porosity value of $37 \%$ identified by Jean-Marc Barnola using porosity measurements of several ice cores from Greenland and Antarctica (Goujon et al., 2003) corresponds to a total porosity of approximately 0.1 for the two data sets (Summit and B53) that are affected by the cut-pore effect (displayed in Fig. 2b).

Even though gas enclosure for a single layer occurs at the same critical porosity, sealed layers may have variable air contents. Above the close-off depth, we determine average coefficients of variation for the total porosity of $1.3 \%$ for B53, $1.8 \%$ for B49 and 2.5\% for RECAP_S2. Higher porosity variability will lead to a larger amount of shallowly trapped pores, thereby increasing the air content $V$ (Stauffer et al., 1985). In our case, the effect of shallow trapping can be estimated from the different slopes of the lock-in curves given in Fig. 2a, yielding possible increases in air content of about $2 \%$ for B49 and $8 \%$ for RECAP_S2 in comparison with B53. This implicitly assumes that closed and open porosity undergo the same compaction as the firn densifies and thus has to be interpreted as the maximum possible influence of shallow trapping. In addition, the lock-in zone extends over a depth range of approximately $7 \mathrm{~m}$ for B53, $9 \mathrm{~m}$ for B49 and $15 \mathrm{~m}$ for RECAP_S2. Larger lock-in zones are expected to cause enhanced sealing effects (i.e., permeable layers being sealed by impermeable ones above). This further increases the air content (Stauffer et al., 1985). However, the effect is hard to quantify as our measurements do not yield information about the spatial extent of horizontal layers, and it does not take into account pressure adjustment within the lock-in zone, which is happening on a much shorter timescale compared to diffusion (Buizert and Severinghaus, 2016). Nonetheless, it may explain the 8 and $27 \%$ larger air contents for B49 and RECAP_S2 (compared to B53), respectively, that $V$ measurements for deep ice cores would predict according to the observed temperature dependence (Martinerie et al., 1992). In return, even though we do not observe this temperature dependence for the gas enclosure within single layers, it is a signal that seems to originate from the lock-in zone, presumably as a consequence of a distinct density layering.

We conclude that $V$ measurements may yield multiplelayer averages of pore volumes at gas enclosure. They should only be interpreted with great caution in regard to the sealing of single layers. The post-coring loss of enclosed air is an error source we can neither quantify nor rule out. For the Camp Century core, about $10 \%$ lower air contents were observed after 35 years of storage (Vinther et al., 2009), although a systematic error due to the different measurement setups is possible.

\section{Implications}

For the EDC core (East Antarctica), $86 \%$ of the variance in $V$ cannot be explained by air pressure or temperature changes. An anticorrelation with local insolation was found and suggested as a new proxy (Raynaud et al., 2007). The same insolation signature was found for the $V$ record of the NGRIP core (Greenland), but the underlying physical mechanisms are not yet resolved (Eicher et al., 2016). Based on our results, we rule out the idea of other properties influencing the porosity at gas enclosure for single layers as we do not even observe a temperature dependence. Instead, we suggest increased sealing effects and shallow trapping due to larger porosity variability of the layered snowpack as an explanation. Reasons for the enhanced layering may be changes in the atmospheric conditions, accumulation rate or impurity content, similar to the observed increase in layering during glacials (Augustin et al., 2004).

As indicated by $\delta^{15} \mathrm{~N}$ measurements as a proxy for firn height (Sowers et al., 1992), up-to-date firn air models seem to have difficulties to estimate past lock-in depths for the East Antarctic plateau (Landais et al., 2006; Capron et al., 2013) and to synchronize age dating of individual ice cores (Parrenin et al., 2012). We suggest that incorporation of our results will help to overcome these problems, as current approaches are based on temperature-dependent lockin (Martinerie et al., 1992) and the Barnola model (Goujon et al., 2003). Exemplarily, we estimate the gas-age-iceage difference for the Vostok ice core from the temperature (Jouzel et al., 1987) and accumulation rate (Parrenin et al., 2004) records using the Herron-Langway model (Herron and Langway, 1980). On average, excluding the temperature dependence of the critical porosity reduces the gasage-ice-age difference by well over $10 \%$. For the last glacial more than 1000 years of the 2000-year mismatch with $\delta^{15} \mathrm{~N}$ data (Bender et al., 2006) can be explained this way. We suggest a combination with the effect of impurities on firn densification (Freitag et al., 2013; Breant et al., 2017) as a promising approach to resolve the remaining mismatch. Other effects that are currently not well represented, such as stronger 
layering during the glacials (Bendel et al., 2013), may further influence these values. We see this study as a catalyst for improved firn air and densification models, which will reduce dating uncertainties and allow for more sophisticated reinterpretations of the available trace gas records, in particular due to the reduced coupling to temperature.

Code and data availability. The data shown in the plots are available through the open-access library PANGAEA ${ }^{\circledR}$ (Schaller et al., 2017). If you are interested in using our implementation of the described algorithms or want to work with the raw data, please contact the main author.

Author contributions. JF was responsible for the development of the AWI ICE-CT and pointed out the opportunity for this study to CS. Three-dimensional measurements were carried out by JF for RECAP_S2 and CS for B49 and B53. The segmentation of the 3-D data sets and the evaluation of microstructural parameters was performed by CS, who researched and programmed the necessary algorithms. The results and their implications were discussed and related to the literature by all coauthors. CS prepared the initial manuscript, which was reviewed and improved by all coauthors.

Competing interests. The authors declare that they have no conflict of interest.

Acknowledgements. The authors want to acknowledge Sepp Kipfstuhl and Bo Vinther as those responsible for the drilling of B49/B53 and RECAP_S2, respectively, and Todd Sowers for providing an insight into the RECAP firn air data. The main author wants to thank the German National Merit Foundation (Studienstiftung des deutschen Volkes e.V.) for funding his $\mathrm{PhD}$ project. Last but not least, we are much obliged to Eric Wolff, Christo Buizert and an anonymous referee for their support in greatly improving this paper.

The article processing charges for this open-access publication were covered by a Research

Centre of the Helmholtz Association.

Edited by: Eric Wolff

Reviewed by: Christo Buizert and one anonymous referee

\section{References}

Augustin, L., Barbante, C., Barnes, P. R., et al.: Eight glacial cycles from an Antarctic ice core, Nature, 429, 623-628, 2004.

Bendel, V., Ueltzhöffer, K. J., Freitag, J., Kipfstuhl, S., Kuhs, W. F., Garbe, C. S., and Faria, S. H.: High-resolution variations in size, number and arrangement of air bubbles in the EPICA DML (Antarctica) ice core, J. Glaciol., 59, 972-980, https://doi.org/10.3189/2013JoG12J245, 2013.
Bender, M. L., Floch, G., Chappellaz, J., Suwa, M., Barnola, J.-M., Blunier, T., Dreyfus, G., Jouzel, J., and Parrenin, F.: Gas age-ice age differences and the chronology of the Vostok ice core, 0-100 ka, J. Geophys. Res., 111, D21115, https://doi.org/10.1029/2005JD006488, 2006.

Breant, C., Martinerie, P., Orsi, A., Arnaud, L., and Landais, A.: Modelling firn thickness evolution during the last deglaciation: constraints on sensitivity to temperature and impurities, Clim. Past, 13, 833-853, https://doi.org/10.5194/cp-13-8332017, 2017.

Broadbent, S. R. and Hammersley, J. M.: Percolation processes: I. Crystals and mazes, Mathematical Proceedings of the Cambridge Philosophical Society, 53, 629-641, https://doi.org/10.1017/S0305004100032680, 1957.

Buizert, C. and Severinghaus, J. P.: Dispersion in deep polar firn driven by synoptic-scale surface pressure variability, The Cryosphere, 10, 2099-2111, https://doi.org/10.5194/tc-10-20992016, 2016.

Buizert, C., Martinerie, P., Petrenko, V. V., Severinghaus, J. P., Trudinger, C. M., Witrant, E., Rosen, J. L., Orsi, A. J., Rubino, M., Etheridge, D. M., Steele, L. P., Hogan, C., Laube, J. C., Sturges, W. T., Levchenko, V. A., Smith, A. M., Levin, I., Conway, T. J., Dlugokencky, E. J., Lang, P. M., Kawamura, K., Jenk, T. M., White, J. W. C., Sowers, T., Schwander, J., and Blunier, T.: Gas transport in firn: multiple-tracer characterisation and model intercomparison for NEEM, Northern Greenland, Atmos. Chem. Phys., 12, 4259-4277, https://doi.org/10.5194/acp12-4259-2012, 2012.

Capron, E., Landais, A., Buiron, D., Cauquoin, A., Chappellaz, J., Debret, M., Jouzel, J., Leuenberger, M., Martinerie, P., MassonDelmotte, V., Mulvaney, R., Parrenin, F., and Prie, F.: Glacialinterglacial dynamics of Antarctic firn columns: comparison between simulations and ice core air- $\delta^{15} \mathrm{~N}$ measurements, Clim. Past, 9, 983-999, https://doi.org/10.5194/cp-9-983-2013, 2013.

Eicher, O., Baumgartner, M., Schilt, A., Schmitt, J., Schwander, K., Stocker, T. F., and Fischer, H.: Climatic and insolation control on the high-resolution total air content in the NGRIP ice core, Clim. Past, 12, 1979-1993, https://doi.org/10.5194/cp-12-19792016, 2016.

Enting, I. G.: Statistics of firn closure: a simulation study, J. Glaciol., 39, 133-142, 1993.

Fabre, A., Barnola, J.-M., Arnaud, L., and Chappellaz, J.: Determination of gas diffusivity in polar firn: comparison between experimental measurements and inverse modeling, Geophys. Res. Lett., 27, 557-560, 2000.

Freitag, J., Kipfstuhl, S., and Laepple, T.: Core-scale radioscopic imaging: a new method reveals densitycalcium link in Antarctic firn, J. Glaciol., 59, 1009-1014, https://doi.org/10.3189/2013JoG13J028, 2013.

Ghanbarian, B. and Hunt, A. G.: Universal scaling of gas diffusion in porous media, Water Resour. Res., 50, 2242-2256, https://doi.org/10.1002/2013WR014790, 2014.

Goujon, C., Barnola, J.-M., and Ritz, C.: Modeling the densification of polar firn including heat diffusion: Application to close-off characteristics and gas isotopic fractionation for Antarctica and Greenland sites, J. Geophys. Res., 108, 4792, https://doi.org/10.1029/2002JD003319, 2003.

Gregory, S. A., Albert, M. R., and Baker, I.: Impact of physical properties and accumulation rate on pore close-off in layered 
firn, The Cryosphere, 8, 91-105, https://doi.org/10.5194/tc-8-912014, 2014.

Herron, M. M. and Langway, C. C.: Firn Densification: An Empirical Model, J. Glaciol., 25, 373-385, https://doi.org/10.3189/S0022143000015239, 1980.

Johnsen, S. J., Clausen, H. B., Dansgaard, W., Gundestrup, N. S., Hansson, M., Jonsson, P., Steffensen, J. P., and Sveinbjornsdottir, A. E.: A "deep" ice core from East Greenland, Meddelelser Om Grønland: Geoscience, 29, 1-22, 1992.

Jouzel, J., Lorius, C., Petit, J. R., Genthon, C., Barkov, N. I., Kotlyakov, V. M., and Petrov, V. M.: Vostok ice core: a continuous isotope temperature record over the last climatic cycle (160,000 years), Nature, 329, 403-408, https://doi.org/10.1038/329403a0, 1987.

Jouzel, J., Masson-Delmotte, V., Cattani, O., Dreyfus, G., Falourd, S., Hoffmann, G., Minster, B., Nouet, J., Barnola, J.-M., Chappellaz, J., Fischer, H., Gallet, J. C., Johnsen, S., Leuenberger, M., Loulergue, L., Luethi, D., Oerter, H., Parrenin, F., Raisbeck, G., Raynaud, D., Schilt, A., Schwander, J., Selmo, E., Souchez, R., Spahni, R., Stauffer, B., Steffensen, J. P., Stenni, B., Stocker, T. F., Tison, J. L., Werner, M., and Wolff, E. W.: Orbital and millennial antarctic climate variability over the past 800,000 years, Science, 317, 793-796, https://doi.org/10.1126/science.1141038, 2007.

Koehler, S. A., Hilgenfeldt, S., and Stone, H. A.: Liquid Flow through Aqueous Foams: The Node-Dominated Foam Drainage Equation, Phys. Rev. Lett., 82, 4232-4235, https://doi.org/10.1103/PhysRevLett.82.4232, 1999.

Landais, A., Barnola, J., Kawamura, K., Caillon, N., Delmotte, M., Van Ommen, T., Dreyfus, G., Jouzel, J., Masson-Delmotte, V., Minster, B., Freitag, J., Leuenberger, M., Schwander, J., Huber, C., Etheridge, D., and Morgan, V.: Firn-air $\delta^{15} \mathrm{~N}$ in modern polar sites and glacial-interglacial ice: a model-data mismatch during glacial periods in Antarctica?, Quaternary Sci. Rev., 25, 49-62, https://doi.org/10.1016/j.quascirev.2005.06.007, 2006.

Legrand, M. and Mayewski, P.: Glaciochemistry of polar ice cores: A review, Rev. Geophys., 35, 219-243, https://doi.org/10.1029/96RG03527, 1997.

Loulergue, L., Schilt, A., Spahni, R., Masson-Delmotte, V., Blunier, T., Lemieux, B., Barnola, J.-M., Raynaud, D., Stocker, T. F., and Chappellaz, J.: Orbital and millennial-scale features of atmospheric $\mathrm{CH}_{4}$ over the past 800,000 years, Nature, 453, 383-386, https://doi.org/10.1038/nature06950, 2008.

Martinerie, P., Lipenkov, V. Y., and Raynaud, D.: Correction of aircontent measurements in polar ice for the effect of cut bubbles at the surface of the sample, J. Glaciol., 36, 299-303, 1990.

Martinerie, P., Raynaud, D., Etheridge, D. M., Barnola, J.-M., and Mazaudier, D.: Physical and climatic parameters which influence the air content in polar ice, Earth Planet. Sc. Lett., 112, 1-13, 1992.

Mitchell, L. E., Buizert, C., Brook, E. J., Breton, D. J., Fegyveresi, J., Baggenstos, D., Orsi, A., Severinghaus, J., Alley, R. B., Albert, M., Rhodes, R. H., McConnell, J. R., Sigl, M., Maselli, O., Gregory, S., and Ahn, J.: Observing and modeling the influence of layering on bubble trapping in polar firn, J. Geophys. Res., 120, 2558-2574, https://doi.org/10.1002/2014JD022766, 2015.

Nguyen, T., Tran, T., Willemsz, T., Frijlink, H., Ervasti, T., Ketolainen, J., and Maarschalk, K.: A density based segmentation method to determine the coordination number of a particulate system, Chem. Eng. Sci., 66, 6385-6392, https://doi.org/10.1016/j.ces.2011.08.044, 2011.

Otsu, N.: A Threshold Selection Method from Gray-Level Histograms, IEEE Trans. Syst. Man. Cybern., 9, 62-66, 1979.

Parrenin, F., Remy, F., Ritz, C., Siegert, M. J., and Jouzel, J.: New modeling of the Vostok ice flow line and implication for the glaciological chronology of the Vostok ice core, J. Geophys. Res., 109, D20102, https://doi.org/10.1029/2004JD004561, 2004.

Parrenin, F., Barker, S., Blunier, T., Chappellaz, J., Jouzel, J., Landais, A., Masson-Delmotte, V., Schwander, J., and Veres, D.: On the gas-ice depth difference ( $\Delta$ depth) along the EPICA Dome C ice core, Clim. Past, 8, 1239-1255, https://doi.org/10.5194/cp-8-1239-2012, 2012.

Raynaud, D. and Lebel, B.: Total gas content and surface elevation of polar ice sheets, Nature, 281, 289-291, https://doi.org/10.1038/281289a0, 1979.

Raynaud, D., Lipenkov, V., Lemieux-Dudon, B., Duval, P., Loutre, M.-F., and Lhomme, N.: The local insolation signature of air content in Antarctic ice, A new step toward an absolute dating of ice records, Earth Planet. Sc. Lett., 261, 337-349, https://doi.org/10.1016/j.epsl.2007.06.025, 2007.

Schaller, C. F., Freitag, J., and Eisen, O.: Firn microstructure in the lock-in zone for three polar ice cores, PANGAEA, https://doi.org/10.1594/PANGAEA.879577, 2017.

Schneebeli, M. and Sokratov, S. A.: Tomography of temperature gradient metamorphism of snow and associated changes in heat conductivity, Hydrol. Process., 18, 3655-3665, https://doi.org/10.1002/hyp.5800, 2004.

Schwander, J.: The transformation of snow to ice and the occlusion of gases, in: The Environmental Record in Glaciers and Ice Sheets, edited by: Oeschger, H. and Langway, C. C., John Wiley \& Sons, Chichester, 53-67, 1989.

Schwander, J. and Stauffer, B.: Age difference between polar ice and the air trapped in its bubbles, Nature, 311, 45-47, https://doi.org/10.1038/311045a0, 1984.

Schwander, J., Barnola, J.-M., Andrié, C., Leuenberger, M., Ludin, A., Raynaud, D., and Stauffer, B.: The age of the air in the firn and the ice at Summit, Greenland, J. Geophys. Res., 98, 28312838, https://doi.org/10.1029/92JD02383, 1993.

Schwander, J., Sowers, T., Barnola, J.-M., Blunier, T., Fuchs, A., and Malaizé, B.: Age scale of the air in the summit ice: Implication for glacial-interglacial temperature change, J. Geophys. Res., 102, 19483-19493, https://doi.org/10.1029/97JD01309, 1997.

Severinghaus, J. and Battle, M.: Fractionation of gases in polar ice during bubble close-off: New constraints from firn air $\mathrm{Ne}$, $\mathrm{Kr}$ and Xe observations, Earth Planet. Sc. Lett., 244, 474-500, https://doi.org/10.1016/j.epsl.2006.01.032, 2006.

Sowers, T., Bender, M., Raynaud, D., and Korotkevich, Y. S.: $\delta^{15} \mathrm{~N}$ of $\mathrm{N}_{2}$ in air trapped in polar ice: A tracer of gas transport in the firn and a possible constraint on ice age-gas age differences, J. Geophys. Res., 97, 15683, https://doi.org/10.1029/92JD01297, 1992.

Stauffer, B., Schwander, J., and Oeschger, H.: Enclosure of air during metamorphosis of dry firn to ice, Ann. Glaciol., 6, 108-112, 1985.

Stauffer, D.: Scaling theory of percolation clusters, Phys. Rep., 54, 1-74, https://doi.org/10.1016/0370-1573(79)90060-7, 1979. 
Trudinger, C. M., Enting, I. G., Etheridge, D. M., Francey, R. J., Levchenko, V. A., Steele, L. P., Raynaud, D., and Arnaud, L.: Modeling air movement and bubble trapping in firn, J. Geophys. Res., 102, 6747-6763, https://doi.org/10.1029/96JD03382, 1997.

van der Marck, S. C.: Percolation thresholds of the duals of the face-centered-cubic, hexagonal-close-packed, and diamond lattices, Phys. Rev. E, 55, 6593-6597, https://doi.org/10.1103/PhysRevE.55.6593, 1997.

Vinther, B. M., Buchardt, S. L., Clausen, H. B., Dahl-Jensen, D., Johnsen, S. J., Fisher, D. A., Koerner, R. M., Raynaud, D., Lipenkov, V., Andersen, K. K., Blunier, T., Rasmussen, S. O., Steffensen, J. P., and Svensson, A. M.: Holocene thinning of the Greenland ice sheet, Nature, 461, 385-388, https://doi.org/10.1038/nature08355, 2009.
Weiler, K.: On the composition of firn air and its dependence on seasonally varying atmospheric boundary conditions and the firn structure, Ph.D. thesis, University of Bern, 2008.

Wierman, J. C. and Naor, D. P.: Desirable properties of universal formulas for percolation thresholds, Congressus Numerantium, 125-142, 2003.

Witrant, E., Martinerie, P., Hogan, C., Laube, J. C., Kawamura, K., Capron, E., Montzka, S. A., Dlugokencky, E. J., Etheridge, D., Blunier, T., and Sturges, W. T.: A new multi-gas constrained model of trace gas non-homogeneous transport in firn: evaluation and behaviour at eleven polar sites, Atmos. Chem. Phys., 12, 11465-11483, https://doi.org/10.5194/acp-12-114652012, 2012. 